\title{
Identification and Characterization of Neural Crest-derived Cells in Adult Periodontal Ligament of Mice
}

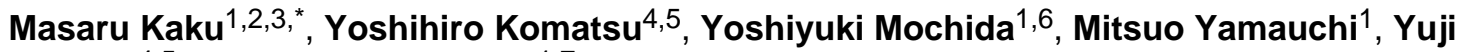 \\ Mishina $^{4,5}$, and Ching-Chang Ko ${ }^{1,7}$ \\ ${ }^{1}$ Dental Research Center, The University of North Carolina at Chapel Hill, Chapel Hill, NC, USA \\ ${ }^{2}$ Niigata University Medical and Dental Hospital, Niigata, Japan \\ ${ }^{3}$ Division of Bio-Prosthodontics, Niigata University Graduate School of Medical and Dental \\ Sciences, Niigata, Japan \\ ${ }^{4}$ Department of Biologic and Materials Sciences, School of Dentistry, University of Michigan, Ann \\ Arbor, MI, USA \\ ${ }^{5}$ Molecular Developmental Biology Group, Laboratory of Reproductive and Developmental \\ Toxicology, National Institutes of Health, Research Triangle Park, North Carolina, USA \\ ${ }^{6}$ Department of Periodontology and Oral Biology, Boston University Goldman School of Dental \\ Medicine, Boston, MA, USA \\ ${ }^{7}$ Department of Orthodontics, The University of North Carolina at Chapel Hill, Chapel Hill, NC, \\ USA
}

\section{Abstract}

Objective-Cells derived from the neural crest (NC) contribute to the development of several adult tissues, including tooth and periodontal tissue. Here, two transgenic lines, Wnt1-Cre/ZEG and $P O-C r e / Z E G$ were analyzed to determine the fate and distribution of neural crest cells (NCCs) in adult mouse periodontal ligament (PDL).

\begin{abstract}
Design-Paraffin-embedded and decalcified histology samples were prepared from Wnt1-Cre/ $Z E G$ and $P 0-C r e / Z E G$ mice that were 4-, 8-, or 12-weeks old. Expression of GFP (NC-derived cells), NC-markers (Slug, AP-2 alpha, HNK-1, p75NTR and Nestin), and mesenchymal stem cell markers (CD29 and STRO-1) were examined using immunohistochemistry.
\end{abstract}

Results-In four-week-old Wnt1-Cre/ZEG mice, $\mathrm{GFP}^{(+)} \mathrm{NC}$-derived cells were specifically detected in the mid-zone of PDL. The $\mathrm{GFP}^{(+)}$cells constituted $1.4 \%$ of all cells in PDL, and this percentage decreased as the mice aged. The distribution and prevalence of $\mathrm{GFP}^{(+)}$cells were comparable between $W n t 1-C r e / Z E G$ and $P 0-C r e / Z E G$ mice. NC-marker ${ }^{(+)}$cells were expressed only in $\mathrm{GFP}^{(+)}$cells while MSC markers were detected only in $\mathrm{GFP}^{(-)}$cells.

Conclusion-The prevalence and specific distribution of NC-derived cells in adult PDL of Wnt1-Cre/ZEG and PO-Cre/ZEG mouse were examined. Interestingly, various NC markers,

(c) 2012 Elsevier Ltd. All rights reserved.

*Corresponding Author: Current Address, Division of Bio-Prosthodontics, Niigata University Graduate School of Medical and Dental Sciences, 2-5274 Gakkouchou-douri, Chuo-ku, Niigata 951-8514, Japan, (TEL) + 81-25-227-2901, (FAX) + 81-25-227-0809, kakum@dent.niigata-u.ac.jp.

Publisher's Disclaimer: This is a PDF file of an unedited manuscript that has been accepted for publication. As a service to our customers we are providing this early version of the manuscript. The manuscript will undergo copyediting, typesetting, and review of the resulting proof before it is published in its final citable form. Please note that during the production process errors may be discovered which could affect the content, and all legal disclaimers that apply to the journal pertain. 
including markers for undifferentiated NCCs, were still expressed at high levels in $\mathrm{GFP}^{(+)}$cells. These observations may indicate that labeled cells in the Wnt1-Cre/ZEG and PO-Cre/ZEG mice did not constituted all NC-derived cells, but rather an interesting subset of NC-derived cells. These findings may be useful in understanding the homeostatic character of the PDL and contribute to establishing successful periodontal tissue maintenance.

\section{Keywords}

Neural crest cells; Neural crest marker; Periodontal ligament

\section{INTRODUCTION}

Periodontal ligament (PDL) is a unique connective tissue that anchors two specialized mineralized tissues, tooth cementum and alveolar bone. Development of the PDL initiates shortly after cementoblasts and fibroblasts form cementum. The cementoblasts and PDL cells originate from the inner layer of dental follicles, which comprise cells of ectomesenchyme origin; thus individual cells are derived from either mesenchyme or the neural crest (NC). Therefore, both cementoblasts and PDL cells are, at least in part, derived from NC. Neural crest cells (NCCs) originate at the neural plate border in the ectodermal and neuroectodermal junction during an early embryonic stage. Cranial NCCs emigrate from $\mathrm{NC}$ during the neural tube formation, 4-somite to 14-somite stage in mice. In mammals, cranial NCCs migrate laterally and ventrally to the craniofacial region and contribute to tooth development $(1,2)$. The NCCs are originally multipotent cells, and their fate is determined during migration to their final destination (3). Recent studies reveal that some NCCs maintain their multipotency even after migration. In fact, undifferentiated multipotent NCCs have been isolated from several NC-derived tissues, including intestine (4), hair follicle (5), skin $(6,7)$, heart (8), and cornea (9), and these populations of NCCs play significant roles in the respective tissues as multipotent stem cells.

Understanding the developmental origin of tissue is vital to ensure proper tissue regeneration or reconstruction. Due to the importance of the NC in tissue development, the $\mathrm{NC}$ is considered a fourth germ layer; therefore, the fate of NCCs has been investigated. Expression of NC markers is generally stage-specific or transient; consequently, it has been difficult to trace derivatives of the NC using only cell surface markers. To study the fate of NCCs, quail-chick transplantation chimeras (10) and DiI labeling system (2) have been developed and utilized. Recently, transgenic mice carrying individual Cre recombinase genes driven by tissue specific promoters and floxed-reporter constructs have been used to genetically mark NCCs for lineage-tracing studies. A proto-oncogene, Wnt $\mathrm{lis}$ expressed during development of the central nervous system, and the Wnt 1 is expressed in NCCs (11). Therefore, Wnt1-Cre transgenic mice (12) that express Cre-recombinase under the control of the Wnt 1 promoter are used to induce Cre-loxP recombination in a NC-specific manner. The Wnt1-Cre line, together with a Cre reporter line $R 26 R(13)$, have been widely used to trace NCCs, and these tracing studies show that NCCs contribute to the formation of dental mesenchyme in tooth development (1); such findings are consistent with the classical observations $(2,10)$. In $W n t 1-C r e / R 26 R$ mice, the majority of PDL cells are shown to be $\mathrm{NC}$ derivative (1). However, the number of non-NC-derived cells increases as tooth development advances $(1,14)$. Currently, several systems for tracing NCCs during development are available; these include transgenic systems and reporter systems; notably, the findings from studies using different systems are not identical $(12,15-18)$. Although, the Wnt1-Cre/R26R mice are often used to trace NC-derivatives, it is necessary to use different NCC tracing systems to confirm that particular findings are reliable. Thus, we also used a line of $P O-C r e$ transgenic mice; in this line, Cre expression is driven by the promoter of the protein $O(P O)$ gene, which encodes a cell adhesion molecule in the immunoglobulin 
superfamily that is specific for NCCs $(9,19)$, to analyze the presence and distribution of NC derivatives in the adult PDL. As a reporter, we used a $Z E G$ Cre reporter line (20), these mice carry a loxP-flanked LacZfollowed by enhanced green fluorescent protein (GFP. Consequently, in mice carrying both Wnt1-Cre (or PO-Cre) and ZEGNC-derived cells are genetically labeled with GFP, allowing detection of the NC lineage throughout embryogenesis and adulthood (21-23).

Here, we examined the distribution of $\mathrm{GFP}^{(+)} \mathrm{NCC}$ derivatives in the adult PDL using Wnt1-Cre/ZEG and PO-Cre/ZEG mice. The distribution of $\mathrm{GFP}^{(+)}$cells was similar in Wnt1-Cre/ZEG and $P O-C r e / Z E G$ mice, but this distribution differed from distribution of $\mathrm{GFP}^{(+)}$cells in Wnt1-Cre/R26R mice. The $\mathrm{GFP}^{(+)}$cells of the PDL were further characterized by assessing the expression of markers for NCCs. Surprisingly, the GFP ${ }^{(+)}$ cells expressed high levels of various NC markers, and these levels were higher than those seen in $\mathrm{GFP}^{(-)}$cells in the PDL of Wnt1-Cre/ZEG mice. Our results demonstrated that the Wnt1-Cre/ZEG and PO-Cre/ZEG mice labeled almost identical subsets of NC-derived cells in mice, but they did not label all NC-derived cells

\section{MATERIALS \& METHODS}

\section{Animals and tissue preparation}

Two transgenic mouse lines, Wnt1-Cre (12) and PO-Cre (15), were separately crossed with lacZ/EGFP $(Z E G)$ reporter mice (20). Genotypes of the transgenic animals were determined using polymerase chain reaction (PCR) assays. Genomic DNA was isolated from ear biopsies. The 5' and 3' primers used to detect the Cre gene were 5'CGAACATCTTCAGGTTCTGCGG-3' and 5'- GTCGATGCAACGAGTGATGAGG-3', respectively, (target size $169 \mathrm{bp}$ ), and primers for the $Z E G$ gene were 5'GTTCATCTGCACCACCGGC-3' and 5'-TTGTGCCCCAGGATGTTGC-3' (target size $284 \mathrm{bp}$ ). All mouse experiments were performed in accordance with the National Institute of Environmental Health Sciences (NIEHS) guidelines regarding the humane care and use of animals in research.

Wnt1-Cre/ZEG or PO-Cre/ZEG mice that were 4-, 8-, or 12 weeks old were euthanized, and the maxilla, including molars and surrounding tissues, were dissected. Mice that carried only $Z E G$ were used as negative controls. The tissue samples were fixed with $4 \%$ formaldehyde, decalcified with $10 \%$ ethylenediaminetetraacetic acid (EDTA), and embedded in paraffin using standard protocols reported elsewhere (24). Sagittal or axial sections (5 $\mu \mathrm{m}$ thick) were prepared and subjected to the following analysis.

The primary and secondary antibodies used in this study were shown in Table 1 . To detect the $\mathrm{GFP}^{(+)} \mathrm{NCCs}$, immunohistochemistry was performed using the avidin-biotin complex method. Tissue sections were deparaffinized and treated with $10 \mathrm{mM}$ citric acid buffer $(\mathrm{pH}$ 6.0) for antigen retrieval. Endogenous horseradish peroxidase (HRP) was quenched with $3 \%$ hydrogen peroxidase $\left(\mathrm{H}_{2} \mathrm{O}_{2}\right)$, and specimens were then incubated overnight with rabbit antiGFP antibody, washed several times with PBS, and then incubated with biotinylated antirabbit IgG for $30 \mathrm{~min}$. After several washes with PBS, samples were incubated with avidinbiotin-HRP mixture for $30 \mathrm{~min}$, and the immunoreactivity was visualized by 3, 3' diamino benzidine tetrahydrochloride (DAB; Vector Laboratories). Hematoxylin was used for counter-staining.

To analyze the expression of NC markers, mesenchymal stem cell (MSC) markers or a cell proliferation marker, in $\mathrm{GFP}^{(+)}$cells double immunofluorescence staining was performed. Following antigen retrieval as described above, sections were incubated with anti-GFP antibody together with one other antibody that is specific to NC cells (i.e., anti-Slug, anti- 
AP-2 alpha, anti-HNK-1, anti-p75NTR, or anti-Nestin antibody), MSC markers (anti-CD29 or anti-STRO-1), or a cell proliferation marker (phospho-Histone H3). The immunoreactivity was visualized by fluorescence conjugated secondary anitibodies. The sections without incubated with primary antibodies were served as negative control. Fluorescently labeled sections were mounted in Prolong Gold antifade reagent containing DAPI (Molecular Probes) and observed under a fluorescence microscope; digital images were captured using CCD image capture (DP-70, Olympus, Tokyo, Japan).

Paraffin-embedded samples $(n=3)$ were prepared from each mouse strain $(n=3)$, and nine sections were analyzed in each experiment. The medial and distal sides of the PDL in the medial root of the first maxillary molar were selected as the observation area in the present study. The numbers of immuno-positive cells and total cells within the observation area were counted, and the percentage of immuno-positive cells within the total cell population was calculated. Statistical analyses were performed using Student's t-test, and a p value less than 0.05 was considered significant.

\section{RESULTS}

\section{Distribution of GFP(+) $^{(+)}$cells in the PDL of Wnt1-Cre/ZEG mice}

To analyze the distribution of $\mathrm{GFP}^{(+)} \mathrm{NCCs}$ in PDL of Wnt1-Cre/ZEG mice, we chose 4weekold mice because root formation is complete by that age. The PDL of the upper first maxillary molar medial root was chosen for sagittal observation, and distal root was chosen for axial observation (Fig. 1a). In Wnt1-Cre/ZEG transgenic mice, $\mathrm{GFP}^{(+)}$cells were detected in the mid-zone of the PDL between bone and cementum, and some were also seen at the surface of bone (Fig. 1b, white arrowhead) and cementum (Fig. 1c, white arrowhead). More $\mathrm{GFP}^{(+)}$cells were evident in the apical region of the PDL than in the cervical region(Fig. 2a). The $\mathrm{GFP}^{(+)}$cells on the bone surface were found only in the apical region of the PDL. GFP ${ }^{(+)}$cells constituted only $1.4 \pm 0.4 \%$ of all cells in the PDL of the medial root in Wnt1-Cre/ZEG mice (Fig. 2b).

In contrast to previous reports, we found that the distribution of $\mathrm{GFP}^{(+)}$cells in Wnt1-Cre/ $Z E G$ mice was not identical to that in $W n t 1-C r e / R 26 R$ mice $(1,14)$. To confirm this observation, we crossed mice that carry a different NC-specific Cre transgene, $\mathrm{PO}-\mathrm{Cre}$ ( 9 , $19)$, with $Z E G$ reporter mice. In the resulting $P O-C r e / Z E G$ mice, the population and distribution of $\mathrm{GFP}^{(+)}$cells were comparable to those in Wnt1-Cre/ZEG mice (Fig. 1d, 2b). We used two different antibodies against GFP and obtained the same results using both antibodies (data not shown). We also confirmed that no $\mathrm{GFP}^{(+)}$cells were detected in mice that were designated the negative control because they carried only ZEG (Fig. 1e, 2b). Ubiquitous expression of $\beta$-gal ${ }^{(+)}$cells was confirmed (Fig. 1f) in the PDL of $Z E G$ reporter mice, verifying that the $Z E G$ reporter system was working properly in the tissue and stage we examined. These observations confirmed that the unique expression pattern of $\mathrm{GFP}^{(+)}$ cells found in the PDL of Wnt1-Cre/ZEG mice was not due to the silencing of the ZEG reporter, rather the observations indicated that the $Z E G$ reporter specifically labeled a subpopulation of NC-derived tissues. A few dendritic-shaped $\mathrm{GFP}^{(+)}$cells, which were presumably fully differentiated peripheral nerve cells, were observed in the PDL of Wnt1$C r e / Z E G$ Fig. $1 \mathrm{~g}$ ) and $P O-C r e / Z E G$ mice (not shown). The $\mathrm{GFP}^{(+)}$cells were also found in odontoblasts in both Wnt 1-Cre/ZEG and PO-Cre/ZEG mice (Fig. 1h, i), but not in $Z E G$ mice (Fig. 1j). The distribution of $\mathrm{GFP}^{(+)}$cells and the $\mathrm{GFP}^{(+)}$cell/total cell ratio in Wnt1-Cre/ $Z E G$ mice were similar to those in PO-Cre/ZEG mice; therefore, we used only Wnt1-Cre/ $Z E G$ mice for the subsequent analyses.

Reportedly, the number of non-NC-derived cells in the PDL of Wnt1-Cre/R26R mice increases as tooth development advanced $(1,14)$. It is known that the second molar of 
rodents develops later than the first molar. Consequently, even in the same histology sample, the PDL of second molar is at the earlier stage of development compared to that of first molar. The percentage of $\mathrm{GFP}^{(+)}$cells in the PDL of second molar was $13.6 \pm 1.0 \%$, that was significantly higher than that of first molar (Fig. 2c). Furthermore, to access the age-related differences in the number of NC-derived cells in the PDL of Wnt1-Cre/ZEG mice, the numbers of $\mathrm{GFP}^{(+)} \mathrm{NC}$-derived cells in 4-, 8- and 12-week-old mice were analyzed. The percentage of $\mathrm{GFP}^{(+)}$cells decreased with age. There were significantly more $\mathrm{GFP}^{(+)}$cells at 4 weeks than at 8 weeks $(1.1 \pm 0.3 \%)$ or at 12 weeks $(1.0 \pm 0.4 \%)$ than at 4 weeks (Fig. 2c).

\section{Expression of NC markers in the PDL of Wnt1-Cre/ZEG mice}

To characterize the $\mathrm{GFP}^{(+)}$cells in the PDL of Wnt1-Cre/ZEG mice, expression of NCmarkers (i.e., Slug, AP-2, HNK-1, p75NTR, or Nestin) was examined by immunofluorescence staining (Fig. 3ae). All NC markers examined were detected within PDL cells. Each NC-marker was evident in less than $0.02 \%$ of all PDL cells. However, NCmarker signal was evident in many $\mathrm{GFP}^{(+)}$cells; specifically, $21.6 \pm 6.1 \%$ of $\mathrm{GFP}^{(+)}$cells were Slug ${ }^{(+)} 32.3 \pm 5.1 \%$ were AP-2 alpha ${ }^{(+)} 22.0 \pm 2.8 \%$ were HNK-1 $1^{(+)} 21.6 \pm 2.1 \%$ were

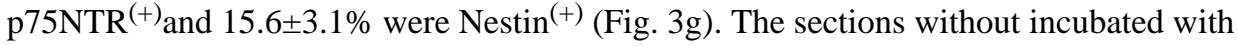
primary antibodies did not show any signal except DAPI (Fig.3f) confirming the specificity of primary antibodies used in this study. Virtually, no cells that expressed a NC marker was also $\mathrm{GFP}^{(-)}$cells. At the developmental stage, the NC markers, such as Slug and AP-2 are expressing in NCCs. However the expression of such markers tends to fade as development progresses and very limited numbers of cells keep expressions of these NCC markers in adults. This is the reason why we need to use a genetically labeled NC traceable system to identify NCC-derived cells in adults. Our data showing that part of $\mathrm{GFP}^{(+)}$cells in Wnt1Cre/ZEG line are still expressing NC markers while $\mathrm{GFP}^{(-)}$cells are not. It may suggest that, $\mathrm{GFP}^{(+)}$cells in adult Wnt1-Cre/ZEG mice still maintain the characteristics of NCCs at their developmental stage.

\section{Expression of MSC markers and a cell proliferation marker in the PDL of Wnt1-Cre/ZEG mice}

To determine whether the $\mathrm{GFP}^{(+)} \mathrm{NC}$-derived cells remained stem cells, the expression of well-characterized MSC markers, CD29 and STRO-1, was examined. Among the PDL cells, $\mathrm{CD} 29^{(+)}$or STRO- $1^{(+)}$cells were found at $0.4 \pm 0.12 \%$ and $0.4 \pm 0.27 \%$ respectively. Surprisingly, the MSC marker ${ }^{(+)}$cellswere all $\mathrm{GFP}^{(-)}$; none were $\mathrm{GFP}^{(+)}$(Fig. 4a). The MSC marker ${ }^{(+)}$signal indicated that MSCs were located to the peri-vascular in the PDL, as reported previously (25). The red blood cells in the blood vessels were also detected, however these signals are false positive due to their auto-fluorescence property.

To evaluate the cellular proliferative potential of $\mathrm{GFP}^{(+)}$cells in the PDL of Wnt1-Cre/ZEG mice, expression of phospho-Histone $\mathrm{H} 3$ (Ser10), which is a cell proliferation marker that specifically labels cells in mitosis (M)-phase (26), was analyzed using immunofluorescence staining. Cells with phospho-Histone $\mathrm{H} 3$ signal constituted $11.4 \pm 1.5 \%$ of all $\mathrm{GFP}^{(+)}$cells and $0.3 \pm 0.2 \%$ of all $\mathrm{GFP}^{(-)}$cells (Fig. $4 \mathrm{~b}$ ). This observation also confirmed the notion that the $\mathrm{GFP}^{(+)}$cells in the PDL of Wnt1-Cre/ZEG mice represented a distinct subset of NCCs.

\section{DISCUSSION}

Here, we have identified the populations and evaluated the distributions of $\mathrm{GFP}^{(+)} \mathrm{NC}-$ derived cells in the PDL of 4-, 8-, and 12-week-old Wnt1-Cre/ZEG mice. The number of labeled NC-derived cells in the PDL of Wnt1-Cre/ZEG mice was lower than that in the PDL of Wnt1-Cre/R26R mice, which have been analyzed many times. In Wnt1-Cre/R26R mice, a majority of PDL cells are labeled as NC derivatives $(1,14,23)$. Wnt1-Cre/ZEG constructs 
may not label all NC-derived cells in the PDL, but rather they may label only a subpopulation. Consequently, we confirmed the relevancy of the NCtraceable system, which we used, using two different GFP antibodies and two Cre systems that are driven by different NC-specific promoters. Successful expression of the $Z E G$ transgene in a majority of PDL cells was also verified by immuno-detection of $\beta$-gal.

As reported previously, the labeling efficiency of the ZEG system becomes low in adult tissues (27-29), and the increased methylation that is evident in older mice may affect Credependent recombination (27). Thus, it is a formal possibility that the entire NC-derivatives may not labeled in the PDL of Wnt1-Cre/ZEG mice due to the low labeling efficiency of $Z E G$ system in adult. Because of this, it is difficult to exclude a possibility that some of the CD2 $9^{(+)}$or STRO- $1^{(+)}$cells are neural crest origin. However, an interesting result is that a substantial part of $\mathrm{GFP}^{(+)}$cells in the PDL of Wnt1-Cre/ZEG mice expressed multiple NC markers while we do not observe any of these $\mathrm{NC}$ markers in the $\mathrm{GFP}^{(-)}$cell population. The Wnt1-Cre/ZEG mice may label a selected population of NC-derived cells in PDL at adult stages that expressed various NC-markers, including markers expressed in undifferentiated NCCs.

Previously, cells expressing markers of multipotency and NC markers (e.g., HNK-1, p75NTR, and Nestin) were isolated from neurosphere culture PDL cells $(30,31)$. The neurospheres were able to differentiate into, not only mesenchymal lineages, but also neuronal and mesodermal progeny; these findings indicated the presence of undifferentiated NC-derived cells. Moreover, PDL cell-derived neurospheres reportedly forms from less than $0.01 \%$ of all cells in established culture (31). Similarly, we have found that $0.01 \sim 0.02 \%$ of all PDL cells in vivo expressed markers of undifferentiated NCCs. These data indicated that only a small population of NC-derived cells in PDL may maintain the undifferentiated nature of NCCs.

Interestingly, the $\mathrm{GFP}^{(+)}$cells in PDL of Wnt1-Cre/ZEG mice did not express CD29 or STRO-1, which are well-known MSC markers. Various types of stem cells have been isolated from periodontal tissue, such as stem cells from exfoliated deciduous teeth (SHED) (32), dental pulp stem cells (DPSCs)(33), periodontal ligament stem cells (PDLSCs) (25) etc. These are characterized as MSCs based on three criteria: they have colony-forming ability, they have multi-differentiating potency, and they express MSC markers-including CD29 $(34,35)$ and STRO- $1(25,36-38)$. We found that only $0.4 \%$ of the cells in the PDL of Wnt1-Cre/ZEG mice were either CD29 $9^{(+)}$or STRO-1 ${ }^{(+)}$cells, and none of these cells were $\mathrm{GFP}^{(+)}$cells. Previous studies clearly demonstrate the substantial contribution of NCderived cells during the developmental stages of periodontal tissue $(1,39,40)$, however, non-NC derived cells become evident as tissue development progresses $(1,14)$. Recent studies have revealed that bone marrow-derived circulating MSCs are found in peripheral blood vessels and are thought to be delivered to the mesenchymal organs, especially to tissues that undergo rapid remodeling (41). In addition, blood vessel-associated pericytes showed similar characteristics as MSC (42). The MSCs in bone marrow, dental pulp and PDL are reported to be localized at the perivascular region further support the characteristics of pericyte (38). In this study, we found CD29(+) or STRO- $1^{(+)}$cells, which are $\mathrm{GFP}^{(-)}$and have perivascular localization. Our findings may confirm the presence of pericyte which are non NC derivative and has MSC-like characteristics, in the adult stage of PDL. These results further support our findings that the $\mathrm{GFP}^{(+)}$and NC marker ${ }^{(+)}$cell population is distinct from previously reported MSCs or pericytes.

To the best of our knowledge, this is the first report to analyze the expression of various NC markers within the adult PDL in vivo. An interesting population of NC-derived cells was identified using two transgenic lines, Wnt1-Cre/ZEG and PO-Cre/ZEG mice, in which NC- 
derived cell can be traced. At this point, we cannot explain the observation that the Wnt1$C r e / Z E G$ system labeled only a select population of NC-derived cells. However, this select population of NC-derived cells expressed various NC-markers (i.e., Slug, AP-2 alpha, HNK-1, p75NTR, and Nestin). Further investigation of this interesting subset of NC-derived cells, including in vitro experiments, may be informative and enhance the understanding of the homeostatic property of the PDL that contributes to establish successful periodontal tissue maintenance.

\section{Acknowledgments}

We thank Dr. Kenichi Yamamura (Kumamoto University, Japan) for the PO-Cre mice. The PO-Cre mice C57BL/6J$\mathrm{Tg}(\mathrm{P0}-\mathrm{Cre}$ )94Imeg (ID 148), were provided by CARD, Kumamoto University, Japan. We also thank Drs. Katsumi Uoshima, Shih-kai Wang, and Sachiko Iseki for their critical reviews of this manuscript. This study was supported by the Japan Society for the Promotion of Science, Grant-in-Aid for Young Scientists 21890081 (M.K.), NIDCR grant K99DE021054 (Y.K.), Intramural Research Program of the NIEHS/NIH grant ES071003-11 (Y.M.), NIDCR grant R01DE020843 (Y.M.), and NIDCR grant K08DE018695 (C-C.K.).

\section{Abbreviations}

$\begin{array}{ll}\text { NC } & \text { neural crest } \\ \text { NCC } & \text { neural crest cell } \\ \text { PDL } & \text { periodontal ligament } \\ \text { GFP } & \text { green fluorescent protein } \\ \text { MSC } & \text { mesenchymal stem cell }\end{array}$

\section{REFERENCES}

1. Chai Y, Jiang X, Ito Y, Bringas P Jr, Han J, Rowitch DH, et al. Fate of the mammalian cranial neural crest during tooth and mandibular morphogenesis. Development. 2000; 127(8):1671-1679. [PubMed: 10725243]

2. Imai H, Osumi-Yamashita N, Ninomiya Y, Eto K. Contribution of early-emigrating midbrain crest cells to the dental mesenchyme of mandibular molar teeth in rat embryos. Dev Biol. 1996; 176(2): 151-165. [PubMed: 8660858]

3. Trentin A, Glavieux-Pardanaud C, Le Douarin NM, Dupin E. Self-renewal capacity is a widespread property of various types of neural crest precursor cells. Proc Natl Acad Sci U S A. 2004; 101(13): 4495-4500. [PubMed: 15070746]

4. Kruger GM, Mosher JT, Bixby S, Joseph N, Iwashita T, Morrison SJ. Neural crest stem cells persist in the adult gut but undergo changes in self-renewal, neuronal subtype potential, and factor responsiveness. Neuron. 2002; 35(4):657-669. [PubMed: 12194866]

5. Sieber-Blum M, Grim M, Hu YF, Szeder V. Pluripotent neural crest stem cells in the adult hair follicle. Dev Dyn. 2004; 231(2):258-269. [PubMed: 15366003]

6. Fernandes KJ, McKenzie IA, Mill P, Smith KM, Akhavan M, Barnabe-Heider F, et al. A dermal niche for multipotent adult skin-derived precursor cells. Nat Cell Biol. 2004; 6(11):1082-1093. [PubMed: 15517002]

7. Wong CE, Paratore C, Dours-Zimmermann MT, Rochat A, Pietri T, Suter U, et al. Neural crestderived cells with stem cell features can be traced back to multiple lineages in the adult skin. J Cell Biol. 2006; 175(6):1005-1015. [PubMed: 17158956]

8. Tomita Y, Matsumura K, Wakamatsu Y, Matsuzaki Y, Shibuya I, Kawaguchi H, et al. Cardiac neural crest cells contribute to the dormant multipotent stem cell in the mammalian heart. J Cell Biol. 2005; 170(7):1135-1146. [PubMed: 16186259]

9. Yoshida S, Shimmura S, Nagoshi N, Fukuda K, Matsuzaki Y, Okano H, et al. Isolation of multipotent neural crestderived stem cells from the adult mouse cornea. Stem Cells. 2006; 24(12): 2714-2722. [PubMed: 16888282] 
10. Couly G, Le Douarin NM. Head morphogenesis in embryonic avian chimeras: evidence for a segmental pattern in the ectoderm corresponding to the neuromeres. Development. 1990; 108(4): 543-558. [PubMed: 2387234]

11. Nusse R, Varmus HE. Many tumors induced by the mouse mammary tumor virus contain a provirus integrated in the same region of the host genome. Cell. 1982; 31(1):99-109. [PubMed: 6297757]

12. Danielian PS, Muccino D, Rowitch DH, Michael SK, McMahon AP. Modification of gene activity in mouse embryos in utero by a tamoxifen-inducible form of Cre recombinase. Curr Biol. 1998; 8(24):1323-1326. [PubMed: 9843687]

13. Soriano P. Generalized lacZ expression with the ROSA26 Cre reporter strain. Nat Genet. 1999; 21(1):70-71. [PubMed: 9916792]

14. Huang X, Bringas P Jr, Slavkin HC, Chai Y. Fate of HERS during tooth root development. Dev Biol. 2009; 334(1):22-30. [PubMed: 19576204]

15. Yamauchi Y, Abe K, Mantani A, Hitoshi Y, Suzuki M, Osuzu F, et al. A novel transgenic technique that allows specific marking of the neural crest cell lineage in mice. Dev Biol. 1999; 212(1):191-203. [PubMed: 10419695]

16. Li J, Chen F, Epstein JA. Neural crest expression of Cre recombinase directed by the proximal Pax3 promoter in transgenic mice. Genesis. 2000; 26(2):162-164. [PubMed: 10686619]

17. Pietri T, Eder O, Blanche M, Thiery JP, Dufour S. The human tissue plasminogen activator-Cre mouse: a new tool for targeting specifically neural crest cells and their derivatives in vivo. Dev Biol. 2003; 259(1):176-187. [PubMed: 12812797]

18. Wang SK, Komatsu Y, Mishina Y. Potential contribution of neural crest cells to dental enamel formation. Biochem Biophys Res Commun. 2011; 415(1):114-119. [PubMed: 22020075]

19. Morikawa S, Mabuchi Y, Niibe K, Suzuki S, Nagoshi N, Sunabori T, et al. Development of mesenchymal stem cells partially originate from the neural crest. Biochem Biophys Res Commun. 2009; 379(4):1114-1119. [PubMed: 19161980]

20. Novak A, Guo C, Yang W, Nagy A, Lobe CG. Z/EG, a double reporter mouse line that expresses enhanced green fluorescent protein upon Cre-mediated excision. Genesis. 2000; 28(3-4):147-155. [PubMed: 11105057]

21. Bhattacherjee V, Mukhopadhyay P, Singh S, Johnson C, Philipose JT, Warner CP, et al. Neural crest and mesoderm lineage-dependent gene expression in orofacial development. Differentiation. 2007; 75(5):463-477. [PubMed: 17286603]

22. Singh S, Bhattacherjee V, Mukhopadhyay P, Worth CA, Wellhausen SR, Warner CP, et al. Fluorescence-activated cell sorting of EGFP-labeled neural crest cells from murine embryonic craniofacial tissue. J Biomed Biotechnol. 2005; 2005(3):232-237. [PubMed: 16192680]

23. Rooker SM, Liu B, Helms JA. Role of Wnt signaling in the biology of the periodontium. Dev Dyn. 2010; 239(1):140-147. [PubMed: 19530172]

24. Kaku M, Uoshima K, Yamashita Y, Miura H. Investigation of periodontal ligament reaction upon excessive occlusal load--osteopontin induction among periodontal ligament cells. J Periodontal Res. 2005; 40(1):59-66. [PubMed: 15613081]

25. Seo BM, Miura M, Gronthos S, Bartold PM, Batouli S, Brahim J, et al. Investigation of multipotent postnatal stem cells from human periodontal ligament. Lancet. 2004; 364(9429):149155. [PubMed: 15246727]

26. Hendzel MJ, Wei Y, Mancini MA, Van Hooser A, Ranalli T, Brinkley BR, et al. Mitosis-specific phosphorylation of histone $\mathrm{H} 3$ initiates primarily within pericentromeric heterochromatin during G2 and spreads in an ordered fashion coincident with mitotic chromosome condensation. Chromosoma. 1997; 106(6):348-360. [PubMed: 9362543]

27. Long MA, Rossi FM. Silencing inhibits Cre-mediated recombination of the Z/AP and Z/EG reporters in adult cells. PLoS One. 2009; 4(5):e5435. [PubMed: 19415111]

28. Zhang XM, Chen BY, Ng AH, Tanner JA, Tay D, So KF, et al. Transgenic mice expressing Crerecombinase specifically in retinal rod bipolar neurons. Invest Ophthalmol Vis Sci. 2005; 46(10): 3515-3520. [PubMed: 16186328]

29. Jullien N, Goddard I, Selmi-Ruby S, Fina JL, Cremer H, Herman JP. Conditional transgenesis using Dimerizable Cre (DiCre). PLoS One. 2007; 2(12):e1355. [PubMed: 18159238] 
30. Coura GS, Garcez RC, de Aguiar CB, Alvarez-Silva M, Magini RS, Trentin AG. Human periodontal ligament: a niche of neural crest stem cells. J Periodontal Res. 2008; 43(5):531-536. [PubMed: 18624954]

31. Techawattanawisal W, Nakahama K, Komaki M, Abe M, Takagi Y, Morita I. Isolation of multipotent stem cells from adult rat periodontal ligament by neurosphere-forming culture system. Biochem Biophys Res Commun. 2007; 357(4):917-923. [PubMed: 17459343]

32. Miura M, Gronthos S, Zhao M, Lu B, Fisher LW, Robey PG, et al. SHED: stem cells from human exfoliated deciduous teeth. Proc Natl Acad Sci U S A. 2003; 100(10):5807-5812. [PubMed: 12716973]

33. Gronthos S, Mankani M, Brahim J, Robey PG, Shi S. Postnatal human dental pulp stem cells (DPSCs) in vitro and in vivo. Proc Natl Acad Sci U S A. 2000; 97(25):13625-13630. [PubMed: 11087820]

34. Sonoyama W, Liu Y, Fang D, Yamaza T, Seo BM, Zhang C, et al. Mesenchymal stem cellmediated functional tooth regeneration in swine. PLoS One. 2006; 1:e79. [PubMed: 17183711]

35. Gronthos S, Brahim J, Li W, Fisher LW, Cherman N, Boyde A, et al. Stem cell properties of human dental pulp stem cells. J Dent Res. 2002; 81(8):531-535. [PubMed: 12147742]

36. Nagatomo K, Komaki M, Sekiya I, Sakaguchi Y, Noguchi K, Oda S, et al. Stem cell properties of human periodontal ligament cells. J Periodontal Res. 2006; 41(4):303-310. [PubMed: 16827724]

37. Gay IC, Chen S, MacDougall M. Isolation and characterization of multipotent human periodontal ligament stem cells. Orthod Craniofac Res. 2007; 10(3):149-160. [PubMed: 17651131]

38. Shi S, Gronthos S. Perivascular niche of postnatal mesenchymal stem cells in human bone marrow and dental pulp. J Bone Miner Res. 2003; 18(4):696-704. [PubMed: 12674330]

39. Han J, Ito Y, Yeo JY, Sucov HM, Maas R, Chai Y. Cranial neural crest-derived mesenchymal proliferation is regulated by Msx1-mediated p19(INK4d) expression during odontogenesis. Dev Biol. 2003; 261(1):183-196. [PubMed: 12941628]

40. Sasaki T, Ito Y, Xu X, Han J, Bringas P Jr, Maeda T, et al. LEF1 is a critical epithelial survival factor during tooth morphogenesis. Dev Biol. 2005; 278(1):130-143. [PubMed: 15649466]

41. da Silva Meirelles L, Chagastelles PC, Nardi NB. Mesenchymal stem cells reside in virtually all post-natal organs and tissues. J Cell Sci. 2006; 119(Pt 11):2204-2213. [PubMed: 16684817]

42. Tintut Y, Alfonso Z, Saini T, Radcliff K, Watson K, Bostrom K, et al. Multilineage potential of cells from the artery wall. Circulation. 2003; 108(20):2505-2510. [PubMed: 14581408] 

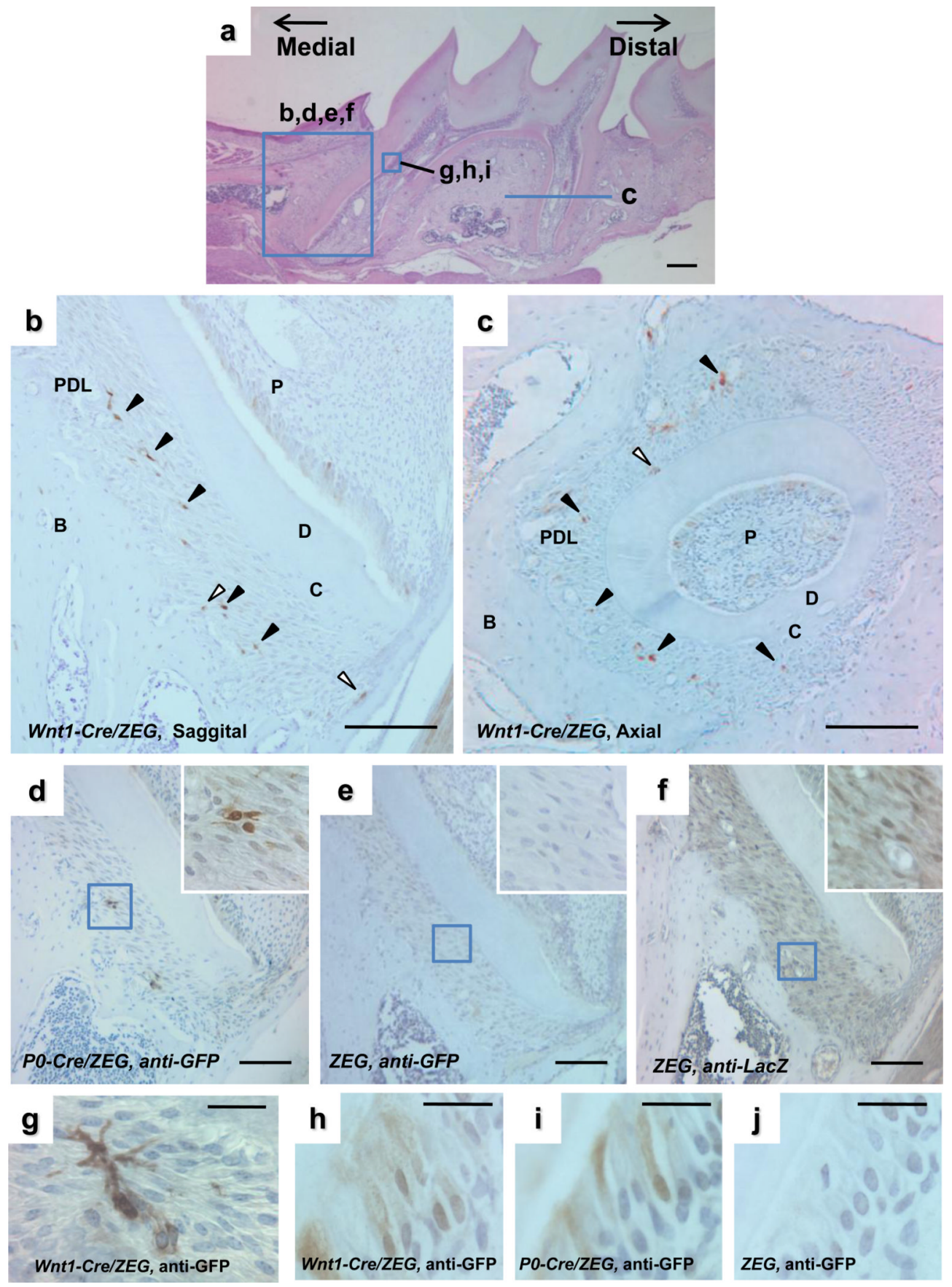

Fig. 1. Distribution of GFP $^{(+)}$NCCs in the PDL of Wnt1-Cre/ZEG mice

Hematoxylin and eosin-stained section shows area under observation which extends from the maxillary first molar (a). Immunohistochemical staining of $\mathrm{GFP}^{(+)}$cells in sagittal (b) and axial (c) sections of the PDL from Wnt1-Cre/ZEG mice. The GFP ${ }^{(+)}$cells (arrowhead) were preferentially distributed in the middle of the PDL, and some were detected at the surface of bone (b, white arrowhead) and cementum (c, white arrowhead). The distribution of $\mathrm{GFP}^{(+)}$cells was similar in Wnt1-Cre/ZEG and PO-Cre/ZEG mice (d), but no GFP(+) cells were found in only $Z E G$ carrying mice (e). The ubiquitous distribution of $\beta$-gal ${ }^{(+)}$cells suggests that the ZEG reporter locus was active in these cells (f). Dendritic-shaped differentiated peripheral nerve cells were detected in the PDL of Wnt1-Cre/ZEG mice (g). 
$\mathrm{GFP}^{(+)}$cells were also found in odontoblasts in Wnt1-Cre/ZEG (h) and P0-Cre/ZEG mice (i), but not in $Z E G$ mice (j). B: bone; C: cementum; D: dentin; P: pulp. Bar: $100 \mu \mathrm{m}$. 

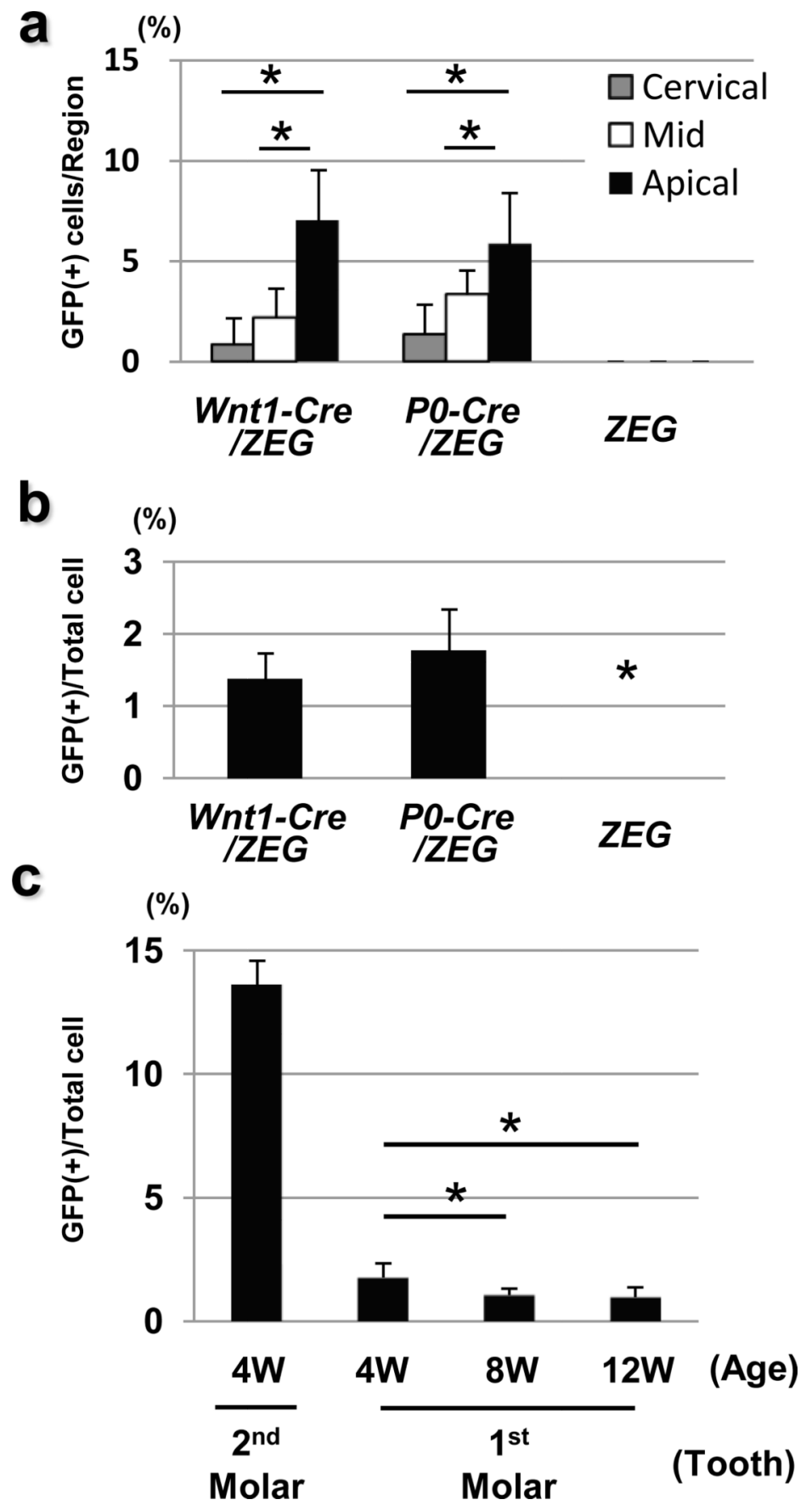

Fig. 2.

The distribution of $\mathrm{GFP}^{(+)}$cells in the different region of PDL in Wnt1-Cre/ZEG mice was compared (a). Apical part of PDL has the most abundant distribution of $\mathrm{GFP}^{(+)}$cells. The number of $\mathrm{GFP}^{(+)}$cells in the PDL of $W n t 1-C r e / Z E G$ and $P 0-C r e / Z E G$ mice was comparable but the $\mathrm{GFP}^{(+)}$was not detected on ZEG mice (b). The percentage of $\mathrm{GFP}^{(+)}$ $\mathrm{NC}$-derived cells in the PDL of different tooth and different age was compared. The $\mathrm{GFP}^{(+)}$ cell ratio was significantly higher in the PDL of $2^{\text {nd }}$ molar compared with first molar. In the PDL of first molar the $\mathrm{GFP}^{(+)}$cell ratio in PDL decreased with age (c) *: Statistical significance $\mathrm{p}<0.05$. 
(a)

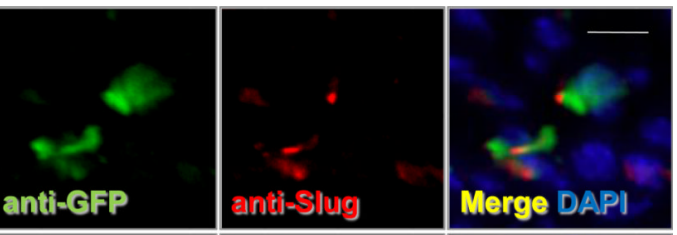

(b)
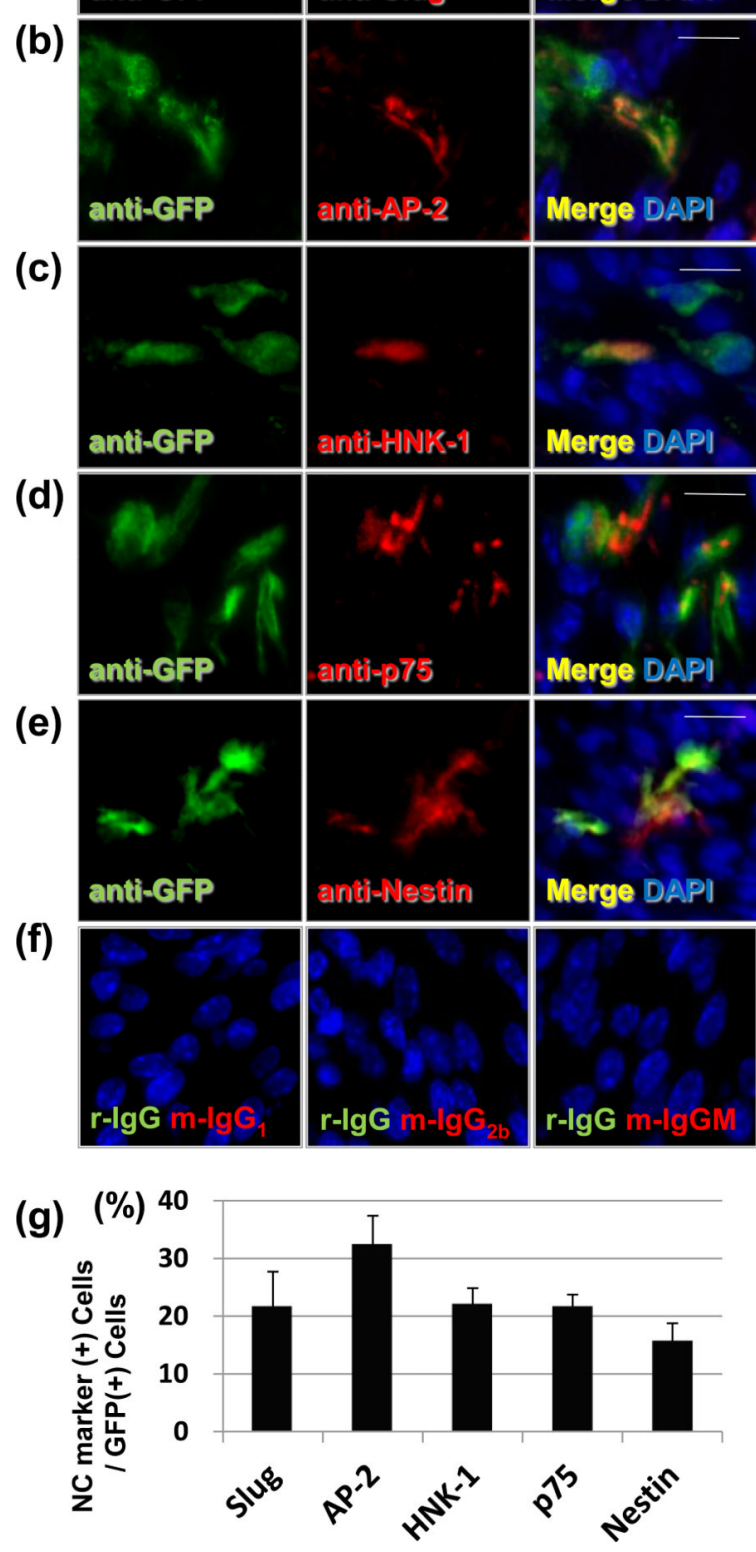

Fig. 3. Expression of neural crest (NC) markers in the PDL of Wnt1-Cre/ZEG mice Immunofluorescence staining to identify $\mathrm{NC}$ markers among $\mathrm{GFP}^{(+)} \mathrm{NCCs}$ in adult PDL cells is shown (a-e). No-signal was detected when samples were reacted without primary antibodies (f). The percentage of $\mathrm{NC}_{\text {marker }}^{(+)}$cells among all $\mathrm{GFP}^{(+)}$cells was $21.6 \pm 6.1 \%$ for Slug, $32.3 \pm 5.1 \%$ for AP-2, $22.0 \pm 2.8 \%$ for HNK-1, $21.6 \pm 2.1 \%$ for $\mathrm{p} 75$, and $15.6 \pm 3.1 \%$ for Nestin (g). Bar: $20 \mu \mathrm{m}$. 
(a)
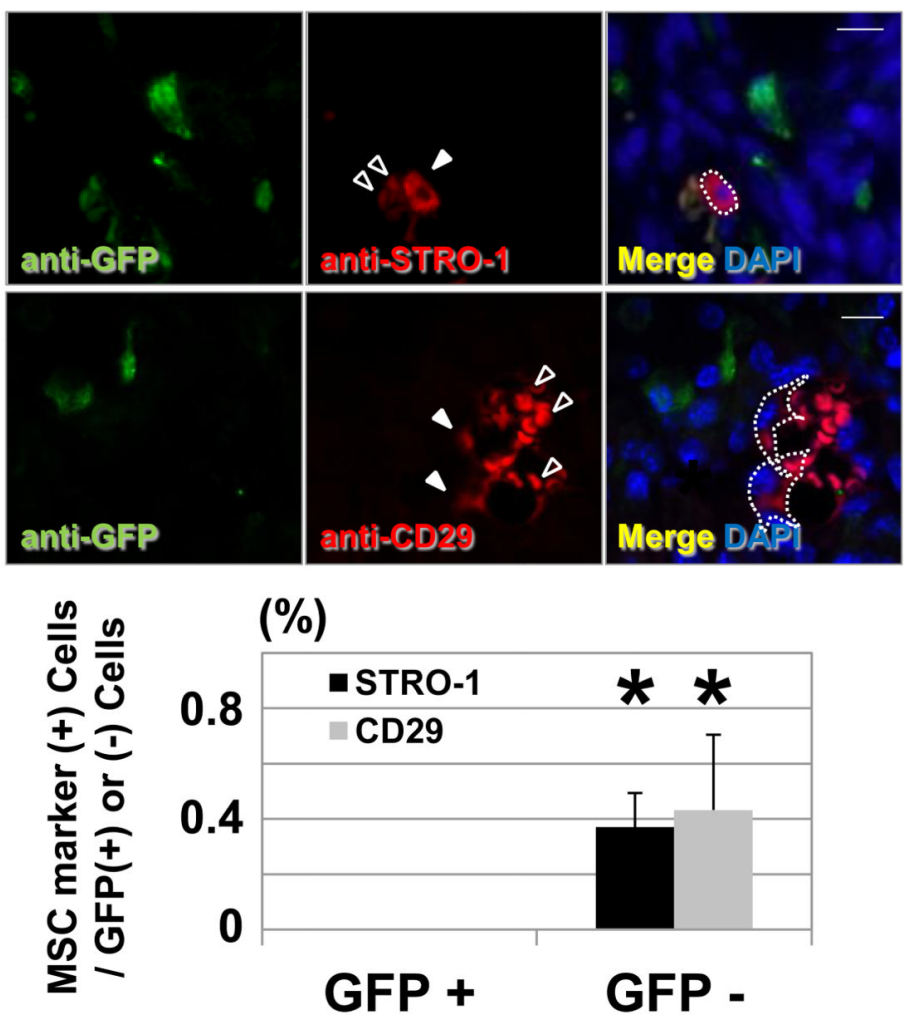

(b)
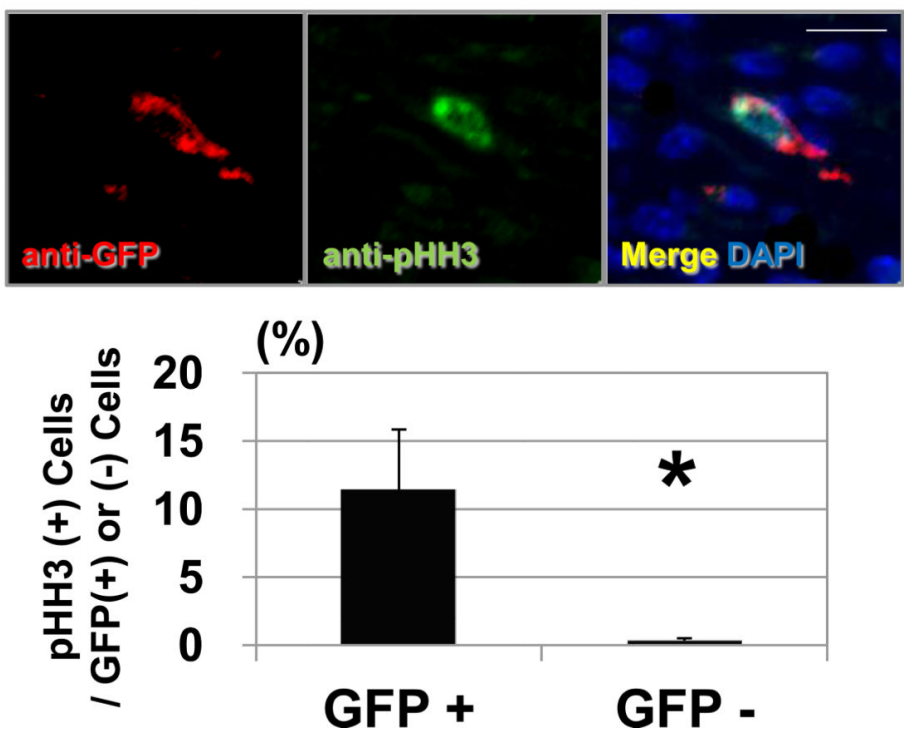

Fig. 4. Expression of mesenchymal stem cell (MSC) markers and a cell proliferation marker in the PDL of Wnt1-Cre/ZEG mice

Immunofluorescence staining of CD29 and STRO-1 on PDL cells (a). CD29 or STRO-1 ${ }^{(+)}$ cells were found only on $\mathrm{GFP}^{(-)}$cells and showed perivascular localization (arrowheads). Red blood cells are detected due to their autofluorescence property (open arrowheads). The expression of phospho-Histone $\mathrm{H} 3\left(\mathrm{pHH}_{3}\right)^{(+)}$cells among $\mathrm{GFP}^{(+)} \mathrm{NCCs}$ and $\mathrm{GFP}^{(-)}$cells were shown (b). $\mathrm{GFP}^{(+)}$cells showed significantly higher cell proliferation in comparison to GFP $^{(-)}$cells. Bar: $20 \mu \mathrm{m}$. *: Statistical significance $\mathrm{p}<0.05$. 


\section{Table 1}

Primary and secondary antibodies used in this study.

\begin{tabular}{|c|c|c|c|}
\hline Antibody Name & Clone No. & Manufacturer/Distributer & Dilution \\
\hline rabbit anti-GFP & A11122 & Molecular Probes (Carlsbad, CA) & $1: 100$ \\
\hline chicken anti-GFP & ab13970 & abcam (Cambridge, MA) & $1: 200$ \\
\hline biotinylated anti- $\beta$-galactosidase & G1041-42 & US Biological (Massachusetts, MA) & $1: 100$ \\
\hline mouse anti-Slug & $62.1 \mathrm{E} 6$ & DSHB & $1: 100$ \\
\hline mouse anti-AP-2 alpha & $3 \mathrm{~B} 5$ & DSHB & $1: 100$ \\
\hline mouse anti-Nestin & Rat-401 & DSHB & $1: 100$ \\
\hline mouse anti-STRO-1 & STRO-1 & DSHB & $1: 100$ \\
\hline mouse anti-HNK-1 & VC1.1 & Sigma-Aldrich (St. Louis, MO) & $1: 100$ \\
\hline mouse anti-p75 & ME20.4 & Santa Cruz Biotechnology, Inc. (Santa Cruz, CA) & $1: 50$ \\
\hline mouse anti-CD29 & $18 / \mathrm{CD} 29$ & BD Bioscience (Franklin Lakes, NJ) & $1: 100$ \\
\hline rabbit anti-phospho-histone $\mathrm{H} 3$ & Ser10 & Millipore (Temecula, CA) & $1: 100$ \\
\hline Alexa Fluor 488 anti-rabbit IgG & $\mathrm{n} / \mathrm{a}$ & Molecular Probes (Carlsbad, CA) & $1: 100$ \\
\hline Alexa Fluor 488 anti-chicken IgG & $\mathrm{n} / \mathrm{a}$ & Molecular Probes (Carlsbad, CA) & $1: 100$ \\
\hline Alexa Fluor 594 anti-mouse IgG $_{1}$ & $\mathrm{n} / \mathrm{a}$ & Molecular Probes (Carlsbad, CA) & $1: 100$ \\
\hline Alexa Fluor 568 anti-mouse $\operatorname{IgG}_{2 b}$ & $\mathrm{n} / \mathrm{a}$ & Molecular Probes (Carlsbad, CA) & $1: 100$ \\
\hline Alexa Fluor 568 anti-mouse IgM & $\mathrm{n} / \mathrm{a}$ & Molecular Probes (Carlsbad, CA) & $1: 100$ \\
\hline biotinylated anti-rabbit IgG & $\mathrm{n} / \mathrm{a}$ & Vector Laboratories (Burlingame, CA) & $1: 200$ \\
\hline biotinylated anti-chiken IgG & $\mathrm{n} / \mathrm{a}$ & Vector Laboratories (Burlingame, CA) & $1: 200$ \\
\hline
\end{tabular}

DSHB; Developmental Studies Hybridoma Bank, Department of Biology, The University of Iowa 